\title{
HARMONIC AND INTERMODULATION PERFORMANCE OF NONLINEAR ELECTRONIC CIRCUITS
}

\author{
MUHAMMAD TAHER ABUELMA'ATTI \\ King Fahd University of Petroleum and Minerals, Box 203, Dhahran 31261, \\ Saudi Arabia
}

(Received 18 June, 1996; In final form 30 August, 1996)

\begin{abstract}
A unified technique for mathematical modelling of the input output characteristics of nonlinear electronic circuits is presented. This technique can be easily implemented using simple hand computations without recourse to standard curve-fitting techniques, which invariably requires extensive computing facilities and well-developed software. The mathematical model, basically a sine-series function, can easily yield closed-form series expressions for the amplitudes of the output components resulting from a multisinusoidal input signal to nonlinear electronic circuits. The technique is very helpful in analysing nonlinear electronic circuits under different scenarios of input signals.
\end{abstract}

\section{INTRODUCTION}

Electronic circuits incorporating active devices are inherently nonlinear. While this inherent nonlinearity is, generally,considered to be a disadvantage for example in amplifiers and filters, in some applications it may be used to advantage for example in mixers and detectors. Whenever a number of signals of different frequencies pass through a nonlinear circuit, energy is transferred to frequencies that are harmonies and sums and differences of the original frequencies; that is intermodulation products. These harmonics and intermodulation products can severly degrade the performance of an electronic circuit intentionally designed to be linear; for example an amplifier, or it can yield the useful output of an electronic circuit intentionally designed to be nonlinear; for example a mixer. In all cases it is essential for a designer to have a rapid indication of the likely spectrum of output signals, including harmonics and intermodulation 
products, from a nonlinear electronic circuit excited by a multisinusoidal input signal. This requires a tractable mathematical model for the input-output characteristic of the electronic circuit under consideration.

A literature survey indicates that a widely used procedure for evaluating the output spectra of a nonlinear electronic circuit involves derivation of a high-order polynomial approximation to the input-output characteristic ${ }^{(1-4)}$. Two approaches are available for obtening the coefficients of this polynomial approximation. The first approach implies the use of least square-error curve-fitting techniques to approximate a measured (or simulated) set of input-output data points. These curve-fitting techniques invariably demand extensive computing facilities and well developed software. It should be noted, also, that a fit will not necessarily improve by increasing the order of the polynomial. Increasing the order allows the curve to wiggle more in order to come closer to the data. The least square-error criterion assures good fit near an original data point, but in between successive data points the fitted curve may oscillate. As the order of the polynomial function increases, the mean square error is reduced, yet the oscillations increase ${ }^{(5)}$. Moreover, for an nth order polynomial, the harmonics and intermodulation products that can be evaluated are restricted to nth order only. The second approach involves a Taylor series expansion of an available, but untractable, mathematical expression about an operating point ${ }^{(6)}$. The problem arises, however, when the mathematical expression available represents the input variable as a function of the output variable, where as what we would prefer is an expression for the output variable as a function of the input variable ${ }^{(7)}$. This requires a series reversion to get the output variable as a function of the input variable. Another procedure, which is less widely used, is based on performing a Fourier analysis of the output variable waveform. The first step for using this procedure is to develop an accurate sketch of the variation of the output variable with time $e^{(8-11)}$. Then by selecting an even number of equally time-spaced samples of this time-function, it is possible to obtain the amplitudes of the different harmonic components of the output variable. The major limitation of this procedure is that many electronic circuits have inputs at two or more independent frequencies. It is not unlikely that very often these frequencies are such that the ratio of the highest to lowest frequency generated by the nonlinear electronic circuit may be large. And since the size of the time step must be proportional to the highest output frequency expected while the length of the simulation interval must be 
proportional to the lowest output frequency expected, then the analysis of such circuits require a vast number of time points. The application of this procedure is, therefore, very limited to cases with inputs consisting of a relatively small number of independent frequencies that are not widely different. A third procedure, which is especially suitable for use in computer-aided analysis using programs such as SPICE, is to perform a transient analysis of the electronic circuit with a multi-sinusoidal input followed by a Fourier decomposition of the output signal ${ }^{(12)}$. The major drawback of this technique is that it is not computationally simple as it has to be repeated for different input levels. However, it is very accurate particularly when the nonlinearity of the electronic circuit is not well behaved (e.g., nonmonotonic). Alternatively, SPICE can be used to generate a DC transfer characteristic of the circuit ${ }^{(12)}$. The results are then applied to a least squares curve-fitting subroutine that yields a polynomial approximation for the transfer characteristic. Using this polynomial approximation, expressions can be obtained for the output products resulting from a multusinusoidal input. The major advantage of this technique is its computational simplicity as it requires only one simple analysis to predict the output products at any input level ${ }^{(12)}$. SPICE, however, cannot be a substitute for the thought-process provided by a hand analysis using simple models for the transistors ${ }^{(13)}$. A better insight into the operation of circuits and a systematic way of getting a preliminary understanding of the circuit performance can be gained by hand analysis using simple device models. Then circuit simulation, using SPICE, can be used to obtain more accurate results and to verify the results obtained by hand calculations ${ }^{(1,14)}$. Moreover, circuit simulation may suffer a wide range of problems, particularly those arising from the discrete nature of the solution methods used to analyze problems of a continuously nonlinear nature ${ }^{(15)}$.

A fourth procedure, which is not widely used in the literature, uses a sine-series function to represent the nonlinear input-output characteristic of the electronic circuit ${ }^{(16)}$. This technique is attractive since a low-order sine-series function can yield the magnitudes of harmonics and intermodulation products of any order. However, similar to the polynomial approximation, a large number of terms is required to fit realistic data. Although a standard least-square curve-fitting procedure can yield the coefficients of the sine-series, this demands extensive computing facilities and well developed software, and yet the desired accuracy may not be attained especially for strong nonlinearities. 
From the above discussion it is obvious that a unified analytical technique for analysing the harmonic and intermodulation performance of nonlinear electronic circuits, which can be easily presented in a class room, is not available. The desired features of such a technique are:

1. being suitable for implementation without recourse to extensive computing facilities and well developed software.

2. can yield closed-form expressions for the amplitudes of the harmonic and intermodulation products resulting from a nonlinear electronic circuit excited by a large number of sinusoidal inputs. This allows the analysis of a wide variety of electronic circuits under different scenarios of input signals.

It is the purpose of this paper to present this technique. In principal, the proposed technique is based on representing the nonlinear input-output characteristic by a sine-series function. The coefficients of this sine-series function can be obtained using simple hand calculations without recourse to standard curve-fitting techniques.

\section{PROPOSED TECHNIQUE}

In general, the nonlinear input-output characteristic, shown in Fig. 1, of an electronic circuit will be available in the form of a discrete number of data points $Y_{n}, n=0,1, \ldots, N$ measured (or simulated) at $X_{n}, n=0,1, \ldots, N$ or calculated from an expression of the form $X_{n}=f\left(Y_{n}\right)$ (or $Y_{n}=f\left(X_{n}\right)$ ) where $X_{1}=X_{\min }, X_{N}=X_{\max }$ and $X_{K}=0,1<K<N$. Both $X_{\min }$ and $X_{\max }$ may be positive or negative and the magnitude of $X_{\max }$ is not necessarily equal to $\mathrm{X}_{\min }$. Also, $\mathrm{Y}_{\min }$ and $\mathrm{Y}_{\max }$ may be positive or negative and are not necessarily equal in magnitude. This implies that the characteristic may or may not be symmetrical. First, we make this set of data periodic with odd symmetry by removing the offset at $X_{K}$ (if any) and utilizing the resulting data in mirror image to generate a complete half peroid $=2 \mathrm{~B}$ as shown in Fig(1). Secondly, we interpolate the resulting nonlinear input-output characteristic between the data points by using $4 \mathrm{~N}$ straight line segments joined end-to-end as shown in Fig(1). The X-values of the segment joins are termed knots. The number of knots and their positions must generally be chosen so that closer knots are placed in regions where $\mathrm{Y}$ is changing rapidly. The knots are not necessarily equally spaced; this 


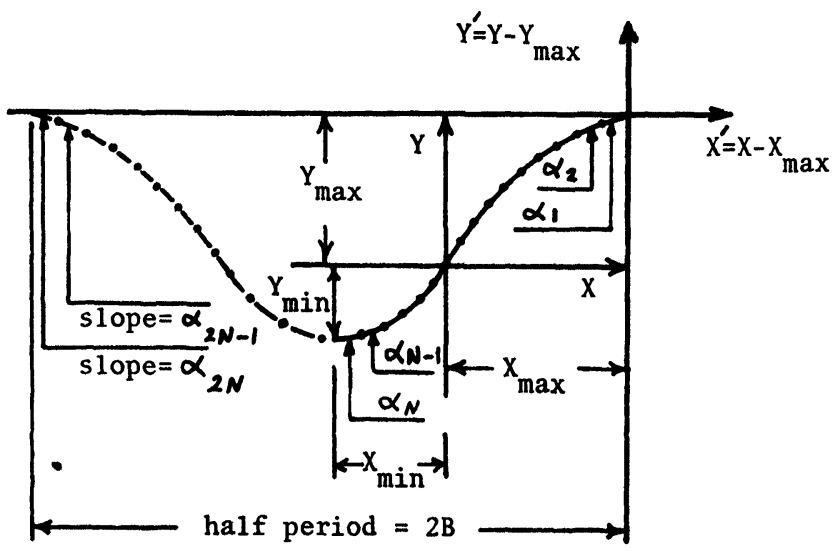

FIGURE 1 Input-Output characteristic of an electronic Circuit (Solid line) shifted and mirror-imaged to generate half period $=2 \mathrm{~B} X-Y$ : Original axes and $X^{\prime}-Y^{\prime}$ : shifted axes

allows the choice of a large number of knots to represent the fine details of the nonlinear input-output characteristic. By denoting the slope of each segment by $\alpha_{n}$, as shown in Fig(1), it is easy, following the procedure described by Kreyszig ${ }^{(17)}$, to show, without performing any integration, that the coefficients, $\gamma_{2 \mathrm{~m}+1}$, of the sine-series function of eqn(1) can be expressed by eqn(2).

$$
\begin{gathered}
\mathrm{Y}-\mathrm{Y}_{\max }=\sum_{\mathrm{m}=0}^{\mathrm{M}} \gamma_{2 \mathrm{~m}+1} \sin \left((2 \mathrm{~m}+1) \pi \frac{\mathrm{X}-\mathrm{X}_{\max }}{2 \mathrm{~B}}\right) \\
\gamma_{2 \mathrm{~m}+1}= \\
\frac{8 \mathrm{~B}}{((2 \mathrm{~m}+1) \pi)^{2}}\left[\alpha_{N} \sin \left(\frac{2 \mathrm{~m}+1}{2} \pi\right)+\sum_{\mathrm{n}=1}^{N-1}\left(\alpha_{\mathrm{n}}-\alpha_{\mathrm{n}+1}\right) \sin \left(\frac{(2 \mathrm{~m}+1) \pi}{2 B} \mathrm{X}_{\mathrm{n}}\right)\right]
\end{gathered}
$$

where $\mathrm{B}=-\left|\mathrm{X}_{\max }-\mathrm{X}_{\min }\right|$.

From eqn(2) it is obvious that, in contrast with the standard least-square-error curve-fitting techniques, calculation of the coefficients $\gamma_{2 m+1}$ of any order $2 m+1$ requires only simple mathematical operations. Also, inspection of eqn(2) suggests that as $2 m+1$ becomes infinite, the sine-series coefficients $\gamma_{2 \mathrm{~m}+1}$ always approach zero.

Using eqn(2), any set of measured, simulated, or calculated data points can be fitted to a sine-series function to any degree of accuracy, by using as many terms as necessary. In fact, for numerical computation using mainframe or personal computers, there is no reason to avoid increasing the number of terms $M$ until the inclusion of the next term is seen to make a negligible contribution towards a best fit criteria; for example the mini- 
mum root-mean-square error. However, for hand computation using pocket calculators, only small values of $\mathrm{M}$ can be used.

\section{EXAMPLES}

To illustrate the effectiveness of the proposed technique, mathematical modelling of the nonlinear input-output characteristics of several electronic circuits will be considered in this section.

\subsection{BJT Input Stages}

The nonlinear input-output characteristic of the bipolar junction transistor (BJT) unbalanced input stage shown in Fig(2) can be expressed as ${ }^{(18)}$

$$
\frac{v_{i}}{(1+\mathrm{N}) \mathrm{V}_{\mathrm{T}}}=-\left[\ln \left(1+\frac{i_{o}}{\mathrm{I}_{\mathrm{T}}}\right)+\mathrm{N} \frac{i_{o}}{\mathrm{I}_{\mathrm{T}}}\right] /(1+\mathrm{N})
$$

and the nonlinear input-output characteristic of the BJT balanced input stage shown in Fig(3) can be expressed as ${ }^{(18)}$

$$
\frac{v_{i}}{2(1+\mathrm{N}) \mathrm{V}_{\mathrm{T}}}=-\left[\ln \left(\frac{1+i_{o} / \mathrm{I}_{\mathrm{T}}}{1-i_{o} / \mathrm{I}_{\mathrm{T}}}\right)+2 \mathrm{~N} \frac{i_{o}}{\mathrm{I}_{\mathrm{T}}}\right] / 2(1+\mathrm{N})
$$

where $\mathrm{N}=\mathrm{R}_{\mathrm{E}} \mathrm{I}_{\mathrm{T}} / \mathrm{V}_{\mathrm{T}}, \mathrm{V}_{\mathrm{T}}$ is the thermal voltage $=26 \mathrm{mV}$ at $300^{\circ} \mathrm{K}$.

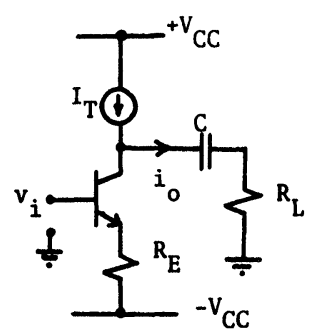

FIGURE 2 Unbalanced BJT input stage

Using the procedure described in the preceding section, eqns(3) and (4) can be represented by the sine-series function of eqn(1) with $Y=i_{0} / I_{T}$ and $\mathrm{X}=v_{i} /(1+\mathrm{N}) \mathrm{V}_{\mathrm{T}}$ for the $\mathrm{BJT}$ unbalanced input stage and $\mathrm{X}=v_{i} / 2(1+\mathrm{N}) \mathrm{V}_{\mathrm{T}}$ for the BJT balanced input stage for any value of the parameter N. Samples of the results obtained are shown in Table I for different values of $\mathrm{N}$. 


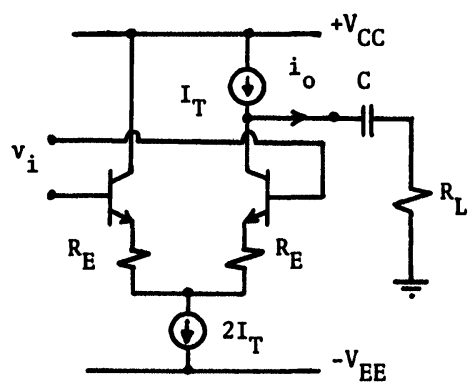

FIGURE 3 Balanced BJT input stage

TABLE I Parameters of BJT input Stages

\begin{tabular}{|c|c|c|c|c|c|c|}
\hline \multirow[b]{3}{*}{$\mathbf{N}$} & \multicolumn{6}{|c|}{ BJT Input Stages } \\
\hline & \multicolumn{3}{|c|}{ Unbalanced Fig (2) } & \multicolumn{3}{|c|}{ Balanced Fig (3) } \\
\hline & 0 & 10 & 100 & 0 & 10 & 100 \\
\hline $\mathrm{Xmax}$ & -0.688 & -0.963 & -0.987 & 2.647 & 1.14 & 1.0064 \\
\hline$Y \max$ & 0.99 & 0.99 & 0.99 & 0.99 & 0.99 & 0.99 \\
\hline B & 5.29 & 2.28 & 2.01 & -5.293 & -2.281 & -2.013 \\
\hline$\gamma_{1}$ & -2.332 & -1.80 & -1.63 & -1.726 & -1.637 & -1.609 \\
\hline$\gamma_{3}$ & -0.47 & 0.132 & 0.176 & 0.446 & 0.241 & 0.186 \\
\hline$\gamma_{5}$ & -0.159 & -0.0304 & -0.062 & 0.165 & -0.0292 & -0.0605 \\
\hline$\gamma_{7}$ & -0.067 & 0.0085 & 0.0309 & -0.0627 & 0.0397 & 0.0343 \\
\hline$\gamma_{9}$ & -0.0351 & -0.0029 & -0.0183 & -0.0255 & -0.00316 & -0.0178 \\
\hline$\gamma_{11}$ & -0.0195 & 0.00083 & 0.01195 & 0.0107 & 0.0136 & 0.0139 \\
\hline$\gamma_{13}$ & -0.0125 & -0.00031 & -0.00838 & 0.0037 & -0.00008 & -0.0082 \\
\hline$\gamma_{15}$ & -0.0079 & 0.000097 & 0.006161 & -0.00117 & 0.006 & 0.0074 \\
\hline$\gamma_{17}$ & -0.0058 & -0.00011 & -0.0047 & -0.0008 & 0.00033 & -0.0047 \\
\hline$\gamma_{19}$ & -0.0039 & 0.0001 & 0.00369 & 0.00046 & 0.0031 & 0.0046 \\
\hline$\gamma_{21}$ & -0.0032 & -0.00014 & -0.00297 & -0.00007 & 0.00029 & -0.0029 \\
\hline$\gamma_{23}$ & -0.0022 & 0.00014 & 0.00243 & 0.0001 & 0.00176 & 0.0031 \\
\hline $\begin{array}{l}\text { RRMS } \\
\text { error }\end{array}$ & $2.1 \%$ & $0.05 \%$ & $0.94 \%$ & $0.04 \%$ & $0.68 \%$ & $0.98 \%$ \\
\hline
\end{tabular}




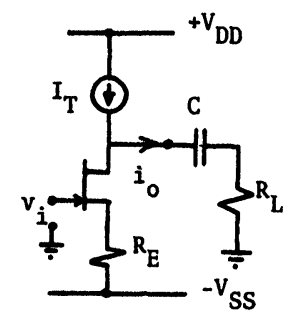

FIGURE 4 Unbalanced JFET input stage

\subsection{JFET Input Stages}

The nonlinear input-output characteristic of the JFET unbalanced input stage shown in Fig(4) can be expressed as ${ }^{(18)}$

$$
\frac{2 \sqrt{2} v_{i}}{(1+\mathrm{N}) \mathrm{V}_{\mathrm{P}}}=-\left[\left(1+\frac{i_{o}}{\mathrm{I}_{\mathrm{T}}}\right)^{\frac{1}{2}}+\mathrm{N} \frac{i_{o}}{2 \mathrm{I}_{\mathrm{T}}}-1\right]\left(\frac{2}{1+\mathrm{N}}\right)
$$

and the nonlinear input-output characteristic of the JFET balanced input stage shown in Fig(5) can be expressed as ${ }^{(18)}$

$$
\frac{\sqrt{2} v_{i}}{(1+\mathrm{N}) \mathrm{V}_{\mathrm{P}}}=-\left[\left(1+\frac{i_{o}}{\mathrm{I}_{\mathrm{T}}}\right)^{\frac{1}{2}}-\left(1-\frac{i_{o}}{\mathrm{I}_{\mathrm{T}}}\right)^{\frac{1}{2}}+\mathrm{N} \frac{i_{o}}{\mathrm{I}_{\mathrm{T}}}\right]
$$

where $\quad N=\frac{2 \sqrt{2} R_{E} I_{T}}{V_{p}}, \quad \mathrm{~V}_{\mathrm{P}}$ is the pinch-off voltage of the JFET, $I_{T}=\frac{I_{D S S}}{2}$, and $\mathrm{I}_{\mathrm{DSS}}$ the drain current at pinch-off for zero gate-to-source voltage.

Using the procedure described in the preceding section, eqns(5) and (6) can be represented by the sine-series function of eqn(1), with $Y=i_{o} / I_{T}$ and $X=\frac{2 \sqrt{2} v_{i}}{(I+N) V p}$ for the JFET unbalanced input stage and $X=\frac{\sqrt{2} v_{i}}{(I+N) V p}$ for the balanced JFET input stage, for any value of the parameter N. Samples of the results obtained for different values of $\mathrm{N}$ are shown, in Table II. 


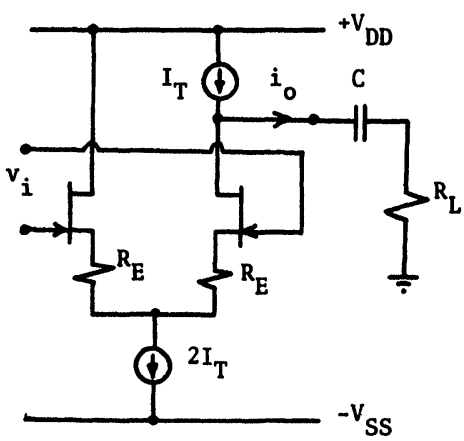

FIGURE 5 Balanced JFET input Stage

TABLE II Parameters of JFET input Stages

\begin{tabular}{|c|c|c|c|c|c|c|}
\hline & \multicolumn{6}{|c|}{ JFET Input Stages } \\
\hline & \multicolumn{3}{|c|}{ Unbalanced Fig(4) } & \multicolumn{3}{|c|}{ Balanced Fig(5) } \\
\hline $\mathrm{N}$ & 0 & 10 & 100 & 0 & 10 & 100 \\
\hline $\mathrm{Xmax}$ & -0.821 & -0.975 & -0.988 & -1.311 & -1.0192 & -0.9932 \\
\hline$Y \max$ & 0.99 & 0.99 & 0.99 & 0.99 & 0.99 & 0.99 \\
\hline B & 2.621 & 2.038 & 1.986 & 2.621 & 2.038 & 1.986 \\
\hline$\gamma_{1}$ & -1.985 & -1.654 & -1.611 & -1.653 & -1.611 & -1.606 \\
\hline$\gamma_{3}$ & -0.042 & 0.166 & 0.177 & 0.277 & 0.19 & 0.179 \\
\hline$\gamma_{5}$ & -0.0227 & -0.0575 & -0.0635 & 0.00263 & -0.0577 & -0.0635 \\
\hline$\gamma_{7}$ & -0.00086 & 0.0279 & 0.0323 & 0.0276 & 0.0341 & 0.0329 \\
\hline$\gamma_{9}$ & -0.005 & -0.016 & -0.0195 & 0.000018 & -0.0169 & -0.0195 \\
\hline$\gamma_{11}$ & 0.00041 & 0.011 & 0.01297 & 0.00824 & 0.0135 & 0.01331 \\
\hline$\gamma_{13}$ & -0.0021 & -0.0075 & -0.0093 & -0.00043 & -0.0078 & -0.0093 \\
\hline$\gamma_{15}$ & 0.00041 & 0.0055 & 0.0069 & 0.0037 & 0.0071 & 0.0071 \\
\hline$\gamma_{17}$ & -0.0011 & -0.0042 & -0.0054 & -0.0004 & -0.0045 & -0.0054 \\
\hline$\gamma_{19}$ & 0.00032 & 0.0033 & 0.0043 & 0.002 & 0.00438 & 0.0045 \\
\hline$\gamma_{21}$ & -0.00066 & -0.0027 & -0.0035 & -0.00038 & -0.0029 & -0.0036 \\
\hline$\gamma_{23}$ & 0.00025 & 0.0022 & 0.0029 & 0.0013 & 0.00295 & 0.003 \\
\hline $\begin{array}{c}\text { RRMS } \\
\text { error }\end{array}$ & $0.14 \%$ & $1.2 \%$ & $1.0 \%$ & $0.36 \%$ & $0.94 \%$ & $1.1 \%$ \\
\hline
\end{tabular}




\subsection{BJT emitter-follower output stage}

The nonlinear input-output characteristic of the BJT emitter-follower output stage shown in $\operatorname{Fig}(6)$ can be expressed as ${ }^{(6)}$,

$$
\frac{v_{\mathrm{i}}-\mathrm{V}_{\mathrm{BEQ}_{2}}}{\mathrm{~V}_{\mathrm{T}}}=\frac{v_{o}}{\mathrm{~V}_{\mathrm{T}}}+\ln \left(1+\frac{v_{o} / \mathrm{V}_{\mathrm{T}}}{\mathrm{N}}\right)
$$

where $\mathrm{N}=\mathrm{R}_{\mathrm{L}} \mathrm{I}_{\mathrm{Q}} / \mathrm{V}_{\mathrm{T}}, \mathrm{V}_{\mathrm{BEQ} 2}$ is the base-to-emitter voltage of $\mathrm{Q}_{2}$, and $\mathrm{I}_{\mathrm{Q}}$ is the dc collector current of $\mathrm{Q}_{2}$.

Using the procedure described in the preceding section, eqn(7) can be represented by the sine-series function of eqn(1) with $\mathrm{Y}=\mathrm{v}_{0} / \mathrm{V}_{\mathrm{T}}$ and $X=\frac{v_{i}-V_{B E Q_{2}}}{V_{T}}$ for any value of the parameter N. Samples of the results obtained are shown in Table III for different values of $\mathrm{N}$.

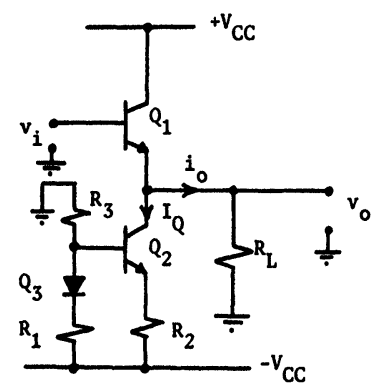

FIGURE 6 BJT Emitter-follower output Stage

TABLE III Parameters of BJT Emitter Follower Output Stage.

\begin{tabular}{|c|c|c|c|}
\hline$N$ & 1 & 10 & 100 \\
\hline Xmax & 1.678 & 10.588 & 99.69 \\
\hline Ymax & 0.99 & 9.9 & 99.0 \\
\hline B & -7.273 & -25.1 & 203.3 \\
\hline$\gamma 1$ & -2.191 & -18.01 & -163.0 \\
\hline$\gamma 3$ & -0.221 & 1.315 & 17.622 \\
\hline$\gamma 5$ & -0.0132 & -0.304 & -6.20 \\
\hline$\gamma 7$ & -0.00165 & 0.0853 & 3.086 \\
\hline$\gamma 9$ & -0.0033 & -0.0286 & -1.826 \\
\hline$\gamma 11$ & -0.0012 & 0.0082 & 1.195 \\
\hline$\gamma 13$ & -0.0012 & -0.0031 & -0.838 \\
\hline$\gamma 15$ & -0.00036 & 0.00097 & 0.616 \\
\hline$\gamma 17$ & -0.0006 & -0.0011 & -0.47 \\
\hline$\gamma 19$ & -0.00014 & 0.001 & 0.3693 \\
\hline$\gamma 21$ & -0.00035 & -0.00139 & -0.297 \\
\hline$\gamma 23$ & -0.00005 & 0.00139 & 0.243 \\
\hline RRMS error & $0.10 \%$ & $0.05 \%$ & $0.94 \%$ \\
\hline
\end{tabular}




\subsection{MOSFET differential amplifier}

The nonlinear input-output characteristic of the MOSFET differential amplifier shown in $\mathrm{Fig}(7)$ can be expressed as ${ }^{(19)}$

$$
\begin{array}{rlrl}
\frac{i_{o}}{\mathrm{I}_{\mathrm{ss}}} & =\sqrt{2} \frac{\mathrm{V}_{\mathrm{id}}}{\sqrt{I_{\mathrm{ss}} / \mathrm{K}}} \sqrt{1-\frac{1}{2}\left(\mathrm{~V}_{\mathrm{id}} / \sqrt{\mathrm{I}_{\mathrm{ss}} / \mathrm{K}}\right)^{2}} & & \text { for }\left|\frac{\mathrm{V}_{\mathrm{id}}}{\sqrt{\mathrm{I}_{\mathrm{ss}} / \mathrm{K}}}\right| \leq 1 \\
& =1 & \text { for }\left|\frac{\mathrm{V}_{\mathrm{id}}}{\sqrt{\mathrm{I}_{\mathrm{ss}} / \mathrm{K}}}\right| \geq 1
\end{array}
$$

where $K=\frac{\mu C_{o x} W}{2 L}$ is the transconductance parameter, $\mu$ is the effective carrier mobility, $\mathrm{C}_{\mathrm{ox}}$ is the capacitance per unit gate area, $\mathrm{W}$ is the channel width, and $L$ is the channel length.

Using the procedure described in the preceding section, eqn(8) can be represented by the sine-series function of eqn(1) with $\mathrm{Y}=\frac{i_{\mathrm{o}}}{\mathrm{I}_{\mathrm{ss}}}$ and $\mathrm{X}=\frac{\mathrm{V}_{\mathrm{id}}}{\sqrt{\mathrm{I}_{\mathrm{ss}} / \mathrm{K}}} \cdot$ Samples of the results obtained are shown in Table IV.

TABLE IV Parameters of the MOSFET differential Amplifier

\begin{tabular}{cc}
\hline Xmax & 0.99 \\
\hline Ymax & 0.99 \\
\hline $\mathrm{B}$ & -1.98 \\
\hline$\gamma_{1}$ & -1.6815 \\
\hline$\gamma_{3}$ & 0.0305 \\
\hline$\gamma_{5}$ & 0.0189 \\
\hline$\gamma_{7}$ & 0.0273 \\
\hline$\gamma 9$ & 0.0053 \\
\hline$\gamma 11$ & 0.0073 \\
\hline$\gamma 13$ & 0.0021 \\
\hline$\gamma 15$ & 0.0029 \\
\hline$\gamma 17$ & 0.00098 \\
\hline$\gamma 19$ & 0.00146 \\
\hline$\gamma 21$ & 0.00053 \\
\hline$\gamma 23$ & 0.00084 \\
\hline RRMS error & $0.31 \%$ \\
\hline
\end{tabular}




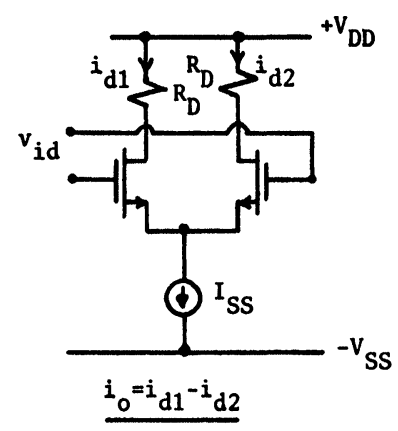

FIGURE 7 MOSFET differential amplifier

\section{HARMONIC AND INTERMODULATION PRODUCTS}

One of the potential applications of the expression of eqn(1) is in the calculation of the harmonic and intermodulation products of nonlinear electronic circuits excited by a multisinusoidal signal of the form

$$
X(t)=A_{b}+\sum_{n=1}^{N} A_{n} \sin \omega_{n} t
$$

where $A_{n}$ is the normalized amplitude of the input sinusoid of frequency $\omega_{n}$ and $A_{b}$ is the normalized biasing.

Substituting eqn(9) into eqn(1) we get

$\mathrm{Y}(\mathrm{t})-\mathrm{Y}_{\max }=\sum_{\mathrm{m}=0}^{\mathrm{M}} \gamma_{2 \mathrm{~m}+1} \sin \left(\frac{(2 \mathrm{~m}+1) \pi}{2 \mathrm{~B}}\left(\sum_{\mathrm{n}=1}^{\mathrm{N}} \mathrm{A}_{\mathrm{n}} \sin \omega_{\mathrm{n}} \mathrm{t}-\mathrm{X}_{\max }^{\prime}\right)\right)$

where $X_{\max }^{\prime}=X_{\max }-A_{b}$.

Using the identities

$$
\begin{aligned}
& \sin (\beta \sin \theta)=2 \sum_{k=0}^{\infty} \mathrm{J}_{2 k+1}(\beta) \sin (2 k+1) \theta \\
& \cos (\beta \sin \theta)=\mathrm{J}_{0}(\beta)+2 \sum_{k=1}^{\infty} \mathrm{J}_{2 k}(\beta) \cos 2 k \theta
\end{aligned}
$$

where $J_{2 k}($.$) is the Bessel function of order 2 k$, eqn $(10)$ reduces to (see Appendix),

$$
\begin{array}{r}
\mathrm{Y}(\mathrm{t})-\mathrm{Y}_{\max }=\sum_{\mathrm{m}=0}^{\infty} \gamma_{2 \mathrm{~m}+1}\left[\cos \left(\frac{(2 \mathrm{~m}+1) \pi}{2 \mathrm{~B}} \mathrm{X}_{\max }^{\prime}\right)\right. \\
\sum_{k_{1}, k_{2}, \ldots, k_{\mathrm{N}}=-\infty}^{\infty} \prod_{\mathrm{n}=1}^{\mathrm{N}} \mathrm{J}_{k_{\mathrm{n}}}\left(\frac{(2 \mathrm{~m}+1) \pi}{2 \mathrm{~B}} \mathrm{~A}_{\mathrm{n}}\right) \sin \left(\sum_{\mathrm{n}=1}^{\mathrm{N}} \mathrm{k}_{\mathrm{n}} \omega_{\mathrm{n}} \mathrm{t}\right)
\end{array}
$$




$$
\begin{gathered}
-\sin \left(\frac{(2 \mathrm{~m}+1) \pi}{2 \mathrm{~B}} \mathrm{X}_{\max }^{\prime}\right) \sum_{k_{1}, k_{2}, \ldots, k_{\mathrm{N}}=-\infty}^{\infty} \prod_{\mathrm{n}=1}^{\mathrm{N}} \mathrm{J}_{k_{\mathrm{n}}}\left(\frac{(2 \mathrm{~m}+1) \pi}{2 \mathrm{~B}} \mathrm{~A}_{\mathrm{n}}\right) \\
\left.\cos \left(\sum_{\mathrm{n}=1}^{\mathrm{N}} k_{\mathrm{n}} \omega_{\mathrm{n}} \mathrm{t}\right)\right] .
\end{gathered}
$$

Noting that

$$
\mathbf{J}_{-k}(\boldsymbol{\beta})=(-)^{k} \mathbf{J}_{k}(\boldsymbol{\beta})
$$

the amplitude of an output product of frequency $\sum_{n=1}^{N} k_{n} \omega_{n}$ and order $\sum_{n=1}^{N}\left|k_{n}\right|$ where $k_{\mathrm{n}}$ is a positive or negative integer or zero, will be given by

$$
\begin{aligned}
& \left(\mathrm{Y}_{k_{1}, k_{2}, \ldots, k_{\mathrm{N}}}\right)_{s}= \\
=2 \sum_{\mathrm{m}=0}^{\mathrm{M}} \gamma_{2 \mathrm{~m}+1} \cos \left(\frac{(2 \mathrm{~m}+1) \pi}{2 \mathrm{~B}} \mathrm{X}_{\max }^{\prime}\right) \prod_{\mathrm{n}=1}^{\mathrm{N}} \mathrm{J}_{\left|k_{\mathrm{n}}\right|}\left(\frac{(2 \mathrm{~m}+1) \pi}{2 \mathrm{~B}} \mathrm{~A}_{\mathrm{n}}\right), & \text { for } \sum\left|k_{\mathrm{n}}\right|=\text { odd }(12 \mathrm{a}) \\
=0 & \text { for } \sum\left|k_{\mathrm{n}}\right|=\text { even }
\end{aligned}
$$

and

$\left(\mathrm{Y}_{k_{1}, k_{2}, \ldots, k_{\mathrm{N}}}\right)_{\mathrm{c}}=$

$=2 \sum_{\mathrm{m}=0}^{\mathrm{M}} \gamma_{2 \mathrm{~m}+1} \sin \left(\frac{(2 \mathrm{~m}+1) \pi}{2 \mathrm{~B}} \mathrm{X}_{\max }^{\prime}\right) \prod_{\mathrm{n}=1}^{\mathrm{N}} \mathrm{J}_{\left|k_{\mathrm{n}}\right|}\left(\frac{(2 \mathrm{~m}+1) \pi}{2 \mathrm{~B}} \mathrm{~A}_{\mathrm{n}}\right)$, for $\Sigma\left|k_{\mathrm{n}}\right|=$ even $(12 \mathrm{~b})$

$=0 \quad$ for $\Sigma\left|k_{\mathrm{n}}\right|=$ odd

The expressions of eqn(12) can, in general, be evaluated using built-in subroutines, available in most mainframe computers, for calculating the Bessel functions. However, in some cases, especially for hand calculations, the following approximations may be useful

and

$$
\mathrm{J}_{k}(\beta) \simeq(\beta / 2)^{k} / k !, \quad \beta \ll 1
$$

$$
\mathrm{J}_{k}(\beta) \simeq \frac{\cos (\beta-\pi / 4-k \pi / 2)}{\sqrt{\beta \pi / 2}}, \quad \beta \gg k+1
$$




\section{SPECIAL CASE}

In this section, the special case of an input signal formed of two equal-amplitude sinusoids of the form

$$
X(t)=A_{o}+A\left(\sin \omega_{1} t+\sin \omega_{2} t\right)
$$

will be considered. Using eqn(12a), the amplitude of an output product of frequency $\omega_{1}$ (or $\left.\omega_{2}\right)$ will be given by

$$
\mathrm{Y}_{1,0}=2 \sum_{\mathrm{m}=0}^{\mathrm{M}} \gamma_{2 \mathrm{~m}+1} \cos \left(\frac{(2 \mathrm{~m}+1) \pi}{2 \mathrm{~B}} \mathrm{X}_{\max }^{\prime}\right) \mathrm{J}_{1}\left(\frac{(2 \mathrm{~m}+1) \pi \mathrm{A}}{2 \mathrm{~B}}\right) \mathrm{J}_{o}\left(\frac{(2 \mathrm{~m}+1) \pi \mathrm{A}}{2 \mathrm{~B}}\right)
$$

and the amplitude of an output third-order intermodulation product of frequency $2 \omega_{1} \pm \omega_{2}$ (or $2 \omega_{2} \pm \omega_{1}$ ) will be given by

$$
\begin{aligned}
& \mathrm{Y}_{1,2}=\mathrm{Y}_{2,1}= \\
& 2 \sum_{\mathrm{m}=0}^{\mathrm{M}} \gamma_{2 \mathrm{~m}+1} \cos \left(\frac{(2 \mathrm{~m}+1) \pi}{2 \mathrm{~B}} \mathrm{X}_{\max }^{\prime}\right) \mathrm{J}_{2}\left(\frac{(2 \mathrm{~m}+1) \pi \mathrm{A}}{2 \mathrm{~B}}\right) \mathrm{J}_{1}\left(\frac{(2 \mathrm{~m}+1) \pi \mathrm{A}}{2 \mathrm{~B}}\right)
\end{aligned}
$$

Similarly, using eqn(12b) the amplitude of an output second-order intermodulation product of frequency $\omega_{1} \pm \omega_{2}$ will be given by

$$
\mathrm{Y}_{1,1}=2 \sum_{\mathrm{m}=0}^{\mathrm{M}} \gamma_{2 \mathrm{~m}+1} \sin \left(\frac{(2 \mathrm{~m}+1) \pi}{2 \mathrm{~B}} \mathrm{X}_{\max }^{\prime}\right)\left[\mathrm{J}_{1}\left(\frac{(2 \mathrm{~m}+1) \pi \mathrm{A}}{2 \mathrm{~B}}\right)\right]^{2}
$$

In a similar way, the amplitudes of harmonics and intermodulation products of any order can be calculated using eqn(12).

Combining eqns(14-16), the relative second-order intermodulation distortion can be exressed as

$$
\mathrm{IM}_{2}=20 \log _{10} \frac{\mathrm{Y}_{1,1}}{\mathrm{Y}_{1,0}}
$$

and the relative third-order intermodulation distortion can be defined as

$$
\mathrm{IM}_{3}=20 \log _{10} \frac{\mathrm{Y}_{2,1}}{\mathrm{Y}_{1,0}}
$$

Using eqns(14-18) and Tables (I-IV) the intermodulation performance of BJT input stages, JFET input stages, BJT emitter-follower output stage, and the MOSFET differential amplifier were calculated and the results are shown in Figs(8)-(11). From Figs(8)-(11), it is obvious that for the balanced BJT and JFET input stages and the MOSFET differential amplifier, the second-order intermodulation products are very small as expected. 


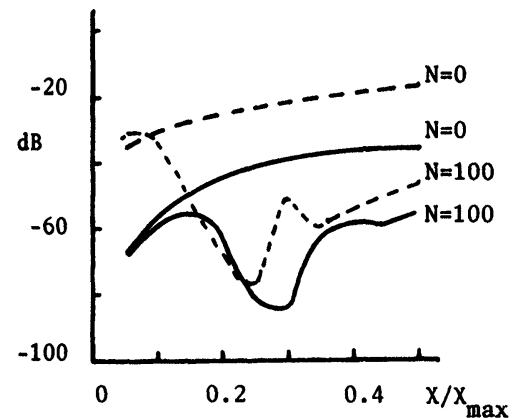

(a) unbalanced

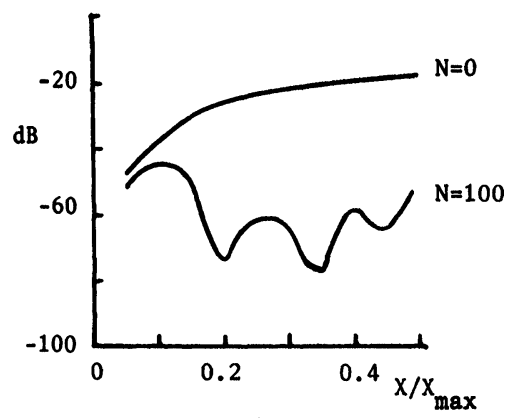

(b) balanced

FIGURE 8 Intermodulation performance of BJT input stages

$$
: \mathrm{IM}_{3}-\mathrm{IM}_{2}
$$

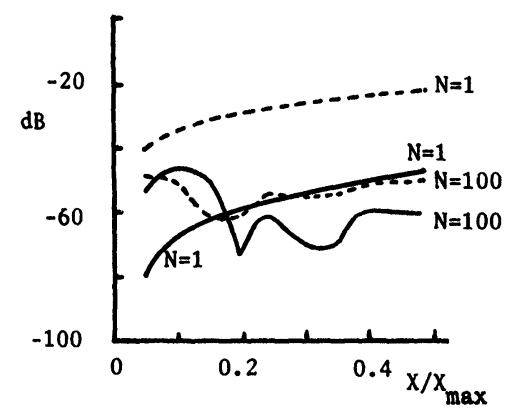

FIGURE 10 Intermodulation performance of BJT Emitter Follower Output Stage $: \mathrm{IM}_{3}$
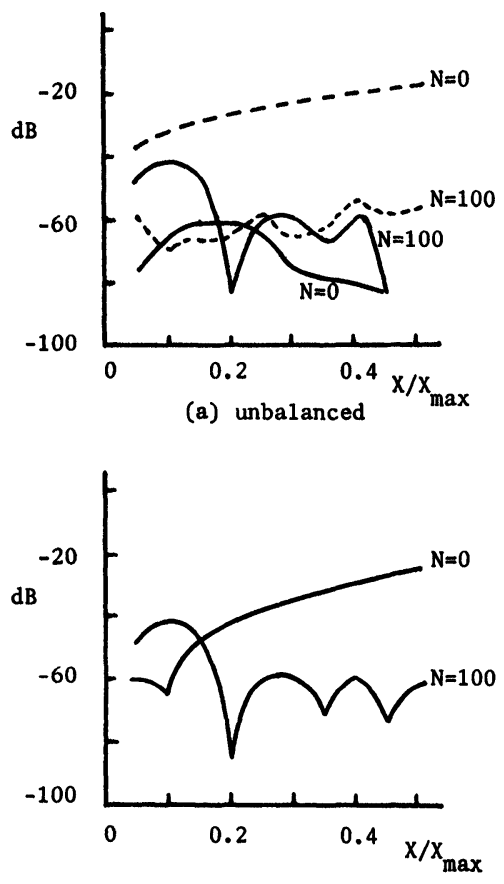

(b) balanced

FIGURE 9 Intermodulation performance of JFET input stages : $\mathrm{IM}_{3}$----: $\mathrm{IM}_{2}$

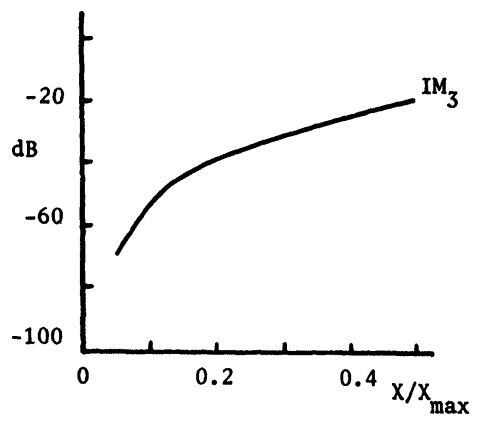

FIGURE 11 Intermodulation performance of MOSFET Differential Amplifier 
Moreover, it is obvious that as $\mathrm{N}$ increases, the third-order intermodulation distortion decreases. This means that increasing $\mathrm{N}$ improves the linearity of the balanced BJT and JFET input stages. This is expected as the increase in $\mathrm{N}$ implies an increase in $\mathrm{R}_{\mathrm{E}}$, which means an increase in the amount of negative feedback, thus reducing the nonlinear distortion effects. Also, it is obvious that the unbalanced BJT and JFET input stages and the BJT emitter-follower output stage suffer from relatively large amounts of second-order intermodulation products. These results are in good agreement with previously published results ${ }^{(18)}$. However, care is necessary if these results are used to compare the large signal performance of circuits considered; a direct comparison is valid only for same sinusoidal input amplitudes. It is worth mentioning also that the nonlinear input-output characteristics of the balanced BJT input stage, balanced JFET input stage, and the MOSFET differential amplifier are symmetric. Thus, no even-order harmonic and intermodulation products are expected. However, the results obtained using the present analysis show nonzero values for the even-order products. These nonzero values arise because of the imprecision inherent in digital computer calculations and should be ignored. It is, therefore, important to read the results carefully. However, in practical circuits, even-order products may result due to the mismatch between the transistors.

\section{SIMULATION RESULTS}

Using the PSPICE student version, the harmonic and intermodulation performance of the circuits of Figs.2-4 can be studied. However, in contrast with the technique presented in this paper, this requires a new run for every change in the input levels. In PSPICE, Probe can be used to perform a Fourier-transform on the data obtained from a tansient analysis. Fig. 12 shows a typical plot for the output current (spectral domain) obtained from the circuit of Fig. 2 with $\mathrm{V}_{\mathrm{b}}=0, \mathrm{~V}_{1}=\mathrm{V}_{2}=8.6 \mathrm{mV}, \mathrm{R}_{\mathrm{E}}=0, \mathrm{I}_{\mathrm{T}}=1 \mathrm{~mA}, \mathrm{~V}_{\mathrm{CC}}=$ $5 \mathrm{~V}, \mathrm{~V}_{\mathrm{EE}}=-0.75 \mathrm{~V}, \mathrm{f}_{1}=1 \mathrm{KH}_{\mathrm{Z}}, \mathrm{f}_{2}=0.8 \mathrm{KH}_{\mathrm{Z}}, \mathrm{R}_{\mathrm{L}}=1 \mathrm{~K}, \mathrm{C}=100 \mu \mathrm{F}$. This corresponds to $A_{b}=0, X / X \max =0.5$. From Fig. 12, the second-order intermodulation IM2 can be calculated, and it is equal to $-18.0 \mathrm{~dB}$. This compares very well with the $-18.5 \mathrm{~dB}$ obtained from Fig. 8(a). However, because the third order intermodulation IM3 is very small, it is hard to measure it from Fig. 12. Similar results were obtained for the other circuits and the difference between the simulation and calculation is always within $\pm 1 \mathrm{~dB}$. 


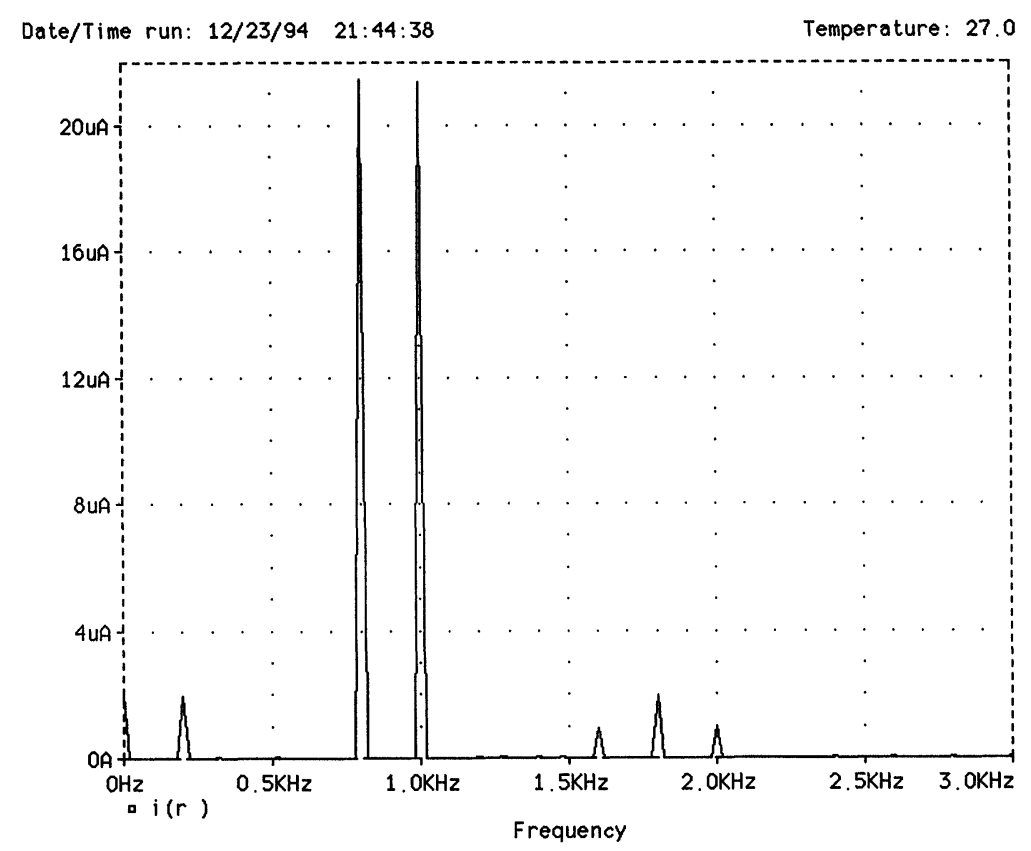

FIGURE 12 Aplot for the output Current (Spectral domain) obtained from the Circuit of Fig. 2 with $\mathrm{V}_{\mathrm{b}}=0 ; \mathrm{V}_{1}=\mathrm{V}_{2}=8.6 \mathrm{mV}, \mathrm{f}_{1}=1 \mathrm{KHz}, \mathrm{f}_{2}=0.8 \mathrm{KHz}$. $\mathrm{I}_{\mathrm{T}}=1 \mathrm{~mA} ; \mathrm{R}_{\mathrm{E}}=0 ; \mathrm{R}_{\mathrm{L}}=1 \mathrm{~K}$, $\mathrm{V}_{\mathrm{cc}}=5 \mathrm{~V}, \mathrm{~V}_{\mathrm{EE}}=-0.75 \mathrm{~V}, \mathrm{C}=100 \mu \mathrm{F}$

\section{CONCLUSION}

In this paper, a simple, yet powerful, technique has been presented for obtaining a mathematical model for the nonlinear input-output characteristic of electronic circuits. The model can be easily implemented using simple hand calculations without recourse to standard curve-fitting techniques, that invariably demand extensive computing facilities and well-developed software. The parameters of the model can be extracted from measured, simulated data, or closed-form analytical expressions. The model can easily yield the amplitudes of the output products resulting from multisinusoidal excitation of nonlinear electronic circuits. In general, calculations of these amplitudes require the computation of ordinary Bessel functions either using subroutines available in most mainframe com- 
puters or using simple approximate expressions that are more appropriate for hand calculations using scientific programmable calculators.

The technique presented in this paper is very simple and can be easily presented in class rooms. Thus, it would be very helpful in explaining the performance of nonlinear electronic circuits under different scenarios of multisinusoidal input signals.

\section{APPENDIX}

Using the identity

$$
\exp \left(\mathrm{i} \beta_{\mathrm{r}} \sin \theta_{\mathrm{r}}\right)=\sum_{\mathrm{m}=-\infty}^{\infty} \mathbf{J}_{\mathrm{m}}\left(\beta_{\mathrm{r}}\right) \exp \left(\mathrm{im} \theta_{\mathrm{r}}\right)
$$

then

$$
\begin{aligned}
& \exp \left(\mathrm{i} \sum_{\mathrm{r}=1}^{\mathrm{K}} \beta_{\mathrm{r}} \sin \theta_{\mathrm{r}}\right)=\prod_{\mathrm{r}=1}^{\mathrm{K}}\left[\sum_{\mathrm{m}=-\infty}^{\infty} \mathrm{J}_{\mathrm{m}}\left(\beta_{\mathrm{r}}\right) \exp \left(\mathrm{im} \theta_{\mathrm{r}}\right)\right] \\
& \text { by interchanging } \prod_{\mathrm{r}=1}^{\mathrm{K}} \text { and } \sum_{\mathrm{m}=-\infty}^{\infty} \text { then } \\
& \exp \left(\mathrm{i} \sum_{\mathrm{r}=1}^{\mathrm{K}} \beta_{\mathrm{r}} \sin \theta_{\mathrm{r}}\right)^{\mathrm{r}=1}=\sum_{\mathrm{m}_{1}, \mathrm{~m}_{2}, \ldots, \mathrm{m}_{\mathrm{K}}=-\infty}^{\infty} \prod_{\mathrm{r}=1}^{\mathrm{K}} \mathrm{J}_{\mathrm{m}_{\mathrm{r}}}\left(\beta_{\mathrm{r}}\right) \exp \left(\mathrm{im}_{\mathrm{r}} \theta_{\mathrm{r}}\right) \\
& =\sum_{\mathrm{m}_{1}, \mathrm{~m}_{2}, \ldots, \mathrm{m}_{\mathrm{K}}=-\infty}^{\infty}\left[\prod_{\mathrm{r}=1}^{\mathrm{K}} \mathrm{J}_{\mathrm{mr}}\left(\beta_{\mathrm{r}}\right)\right] \exp \left(\mathrm{i} \sum_{\mathrm{r}=1}^{\mathrm{K}} \mathrm{m}_{\mathrm{r}} \theta_{\mathrm{r}}\right) \\
& =\sum_{\mathrm{m}_{1}, \mathrm{~m}_{2}, \ldots, \mathrm{m}_{\mathrm{K}}=-\infty}^{\infty}\left(\exp \left(\mathrm{i} \sum_{\mathrm{r}=1}^{\mathrm{K}} \mathrm{m}_{\mathrm{r}} \theta_{\mathrm{r}}\right) \prod_{\mathrm{r}=1}^{\mathrm{K}} \mathrm{J}_{\mathrm{mr}}\left(\beta_{\mathrm{r}}\right)\right)
\end{aligned}
$$

Thus, using the identity

$$
\exp (i \theta)=\cos \theta+i \sin \theta
$$

then

$$
\begin{aligned}
& \cos \left(\sum_{\mathrm{r}=1}^{\mathrm{K}} \beta_{\mathrm{r}} \sin \theta_{\mathrm{r}}\right)+i \sin \left(\sum_{\mathrm{r}=1}^{\mathrm{K}} \beta_{\mathrm{r}} \sin \theta_{\mathrm{r}}\right)= \\
& \sum_{\mathrm{m}_{1}, \mathrm{~m}_{2}, \ldots, \mathrm{m}_{\mathrm{K}}=-\infty}^{\infty}\left[\left(\cos \left(\sum_{\mathrm{r}=1}^{\mathrm{K}} \mathrm{m}_{\mathrm{r}} \theta_{\mathrm{r}}\right)+i \sin \left(\sum_{\mathrm{r}=1}^{\mathrm{K}} \mathrm{m}_{\mathrm{r}} \theta_{\mathrm{r}}\right)\right) \prod_{\mathrm{r}=1}^{\mathrm{K}} \mathrm{J}_{\mathrm{m}_{\mathrm{r}}}\left(\beta_{\mathrm{r}}\right)\right]
\end{aligned}
$$

Equating the real and imaginary parts on both sides, then

$$
\cos \left(\sum_{\mathrm{r}=1}^{\mathrm{K}} \beta_{\mathrm{r}} \sin \theta_{\mathrm{r}}\right)=\sum_{\mathrm{m}_{1}, \mathrm{~m}_{2}, \ldots, \mathrm{m}_{\mathrm{K}}=-\infty}^{\infty} \cos \left(\sum_{\mathrm{r}=1}^{\mathrm{K}} \mathrm{m}_{\mathrm{r}} \theta_{\mathrm{r}}\right) \prod_{\mathrm{r}=1}^{\mathrm{K}} \mathrm{J}_{\mathrm{m}_{\mathrm{r}}}\left(\beta_{\mathrm{r}}\right)
$$

and

$$
\sin \left(\sum_{\mathrm{r}=1}^{\mathrm{K}} \beta_{\mathrm{r}} \sin \theta_{\mathrm{r}}\right)=\sum_{\mathrm{m}_{1}, \mathrm{~m}_{2}, \ldots, \mathrm{m}_{\mathrm{K}}=-\infty}^{\infty} \sin \left(\sum_{\mathrm{r}=1}^{\mathrm{K}} \mathrm{m}_{\mathrm{r}} \theta_{\mathrm{r}}\right) \prod_{\mathrm{r}=1}^{\mathrm{K}} \mathrm{J}_{\mathrm{m}_{\mathrm{r}}}\left(\beta_{\mathrm{r}}\right)
$$


Now equation (10) can be written as

$$
\begin{aligned}
& \mathrm{Y}(\mathrm{t})-\mathrm{Y}_{\max }=\sum_{\mathrm{m}=0}^{\mathrm{M}} \gamma_{2 \mathrm{~m}+1} \cos \left(\frac{(2 \mathrm{~m}+1) \pi}{2 \mathrm{~B}} \mathrm{X}_{\max }\right) \sin \left(\frac{(2 \mathrm{~m}+1) \pi}{2 \mathrm{~B}} \sum_{\mathrm{n}=1}^{\mathrm{N}} \mathrm{A}_{\mathrm{n}} \sin \omega_{\mathrm{n}} \mathrm{t}\right) \\
& -\sum_{\mathrm{m}=0}^{\mathrm{M}} \gamma_{2 \mathrm{~m}+1} \sin \left(\frac{(2 \mathrm{~m}+1) \pi}{2 \mathrm{~B}} \mathrm{X}_{\max }\right) \cos \left(\frac{(2 \mathrm{~m}+1) \pi}{2 \mathrm{~B}} \sum_{\mathrm{n}=1}^{\mathrm{N}} \mathrm{A}_{\mathrm{n}} \sin \omega_{\mathrm{n}} \mathrm{t}\right)
\end{aligned}
$$

Using (A1) and (A2) in, (A3), equation (11) can be obtained.

\section{References}

[1] D.O.Pederson and K.Mayaram, Analog Integrated Circuits for Communication, Kluwer Academic Publishers, Boston, 1991

[2] C.A.Holt, Electronic Circuits, John Wiley \& Sons, New York, 1978

[3] B.Dowding, Principles of Electronics, Prentice Hall, New York, 1988

[4] R. Mauro, Engineering Electronics, Prentice Hall International, NJ, 1989

[5] A.C. Heathman, Methods for intermodulation prediction in communication systems, Ph.D. Thesis, University of Bradford, U.K., 1989

[6] P.R.Gray and R.G. Meyer, Analog Integrated Circuits, John Wiley \& Sons, New York, 1984

[7] M.A.El-Said, F.El-Bayoumi and E.A.Talkhan, Nonlinear distortion cancellation in class A junction transistor amplifier stages, International Journal of Circuit Theory and Applications, Vol.2, 1974, pp.241-256

[8] J.Millman and A. Garbel, Microelectronics, McGraw-Hill, New York, 1988

[9] E.M.Rips, Discrete and Integrated Electronics, Prentice-Hall International, NJ, 1986

[10] M.S.Ghausi, Electronic Devices and Circuits, Holt, Rinehart and Winston, New York, 1985

[11] M.M. Cirovic and J.H.Harter, Electronic Devices, Circuits and Systems, Prentice Hall International, N.J., 1987

[12] S.T.Dupuie and M.Ismail, High Frequency CMOS Transconductors, in Anlogue IC Design, Edited by :C. Toumazou, F.J.Lidgey and D.G.Haigh, Peter Peregrinus Ltd, London, 1990

[13] G.W. Roberts and A.S. Sedra, SPICE for Microelectronic Circuits, Saunders College Publishirg, Fort Worth, 1992

[14] L. V. Hmureik, M.Hettinger, K.S. Gottschalck and F.C. Fitchen, SPICE applications to an Undergraduate Electronics Program, IEEE Transactions on Education, Vol.33, 1990, pp.183-189

[15] P. Mole and H. Rokos, Thecniques for nonlinear circuit simulation, Editorial, IEE Proc.-Circuits Devices Systems, Vol.141, 1994, p.241

[16] M.T.Abuelma'atti, Reduction of Intermodulation in Communications Amplifiers by Pre-Correction Techniques, Ph.D.Thesis, University of Bradford, U.K., 1979

[17] E. Kreyszig, Advanced Engineering Mathematics, John Wiley \& Sons, N.Y., 1983

[18] P. Grade, Slope Distortion and Amplifier Design, Journal of the Audio Engineering Society, Vol.26, 1978, pp. 602-608

[19] A. Sedra and K.C.Smith, Microelectronic Circuits, Saunders College Publishing, Philadelphia, 1991 

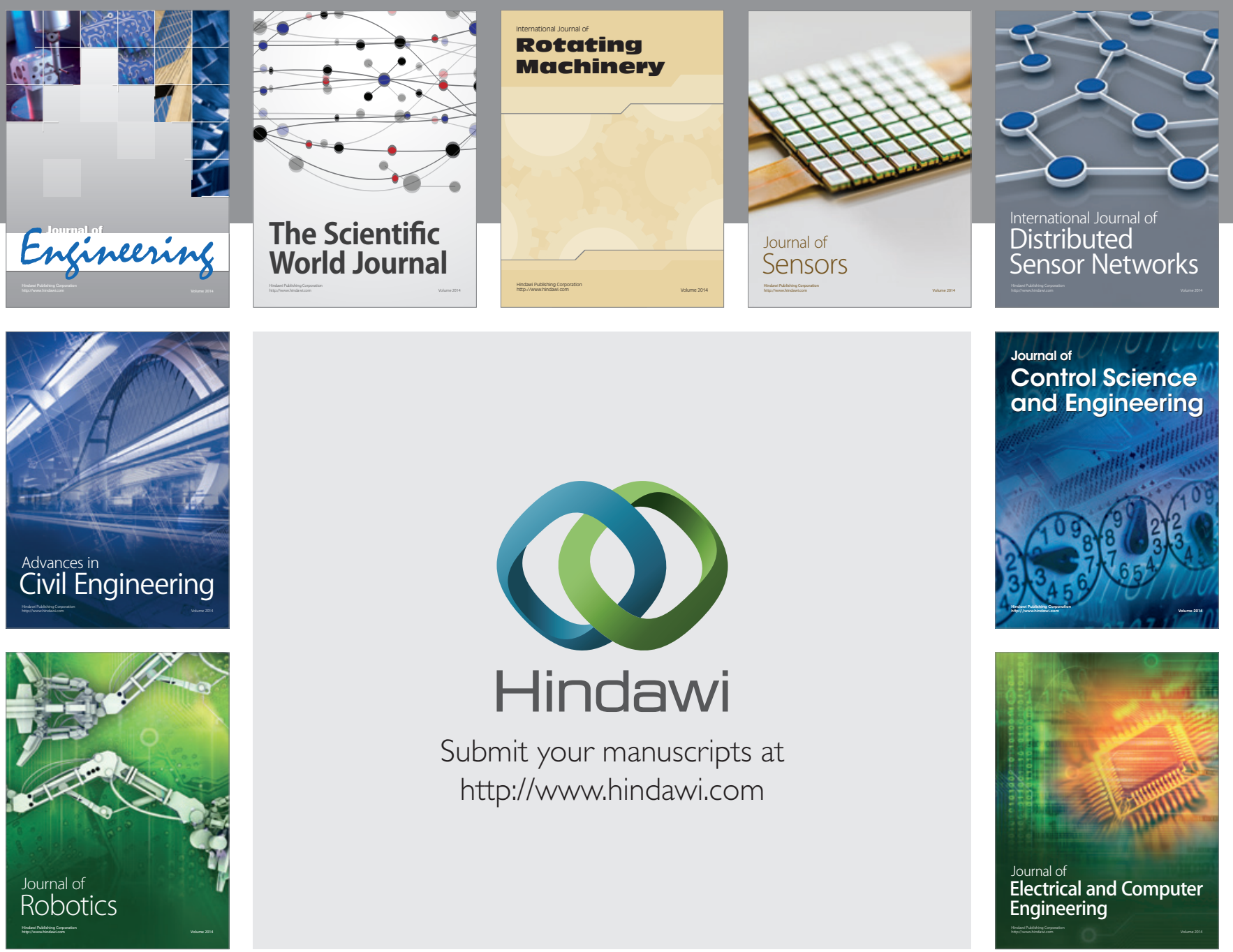

Submit your manuscripts at

http://www.hindawi.com
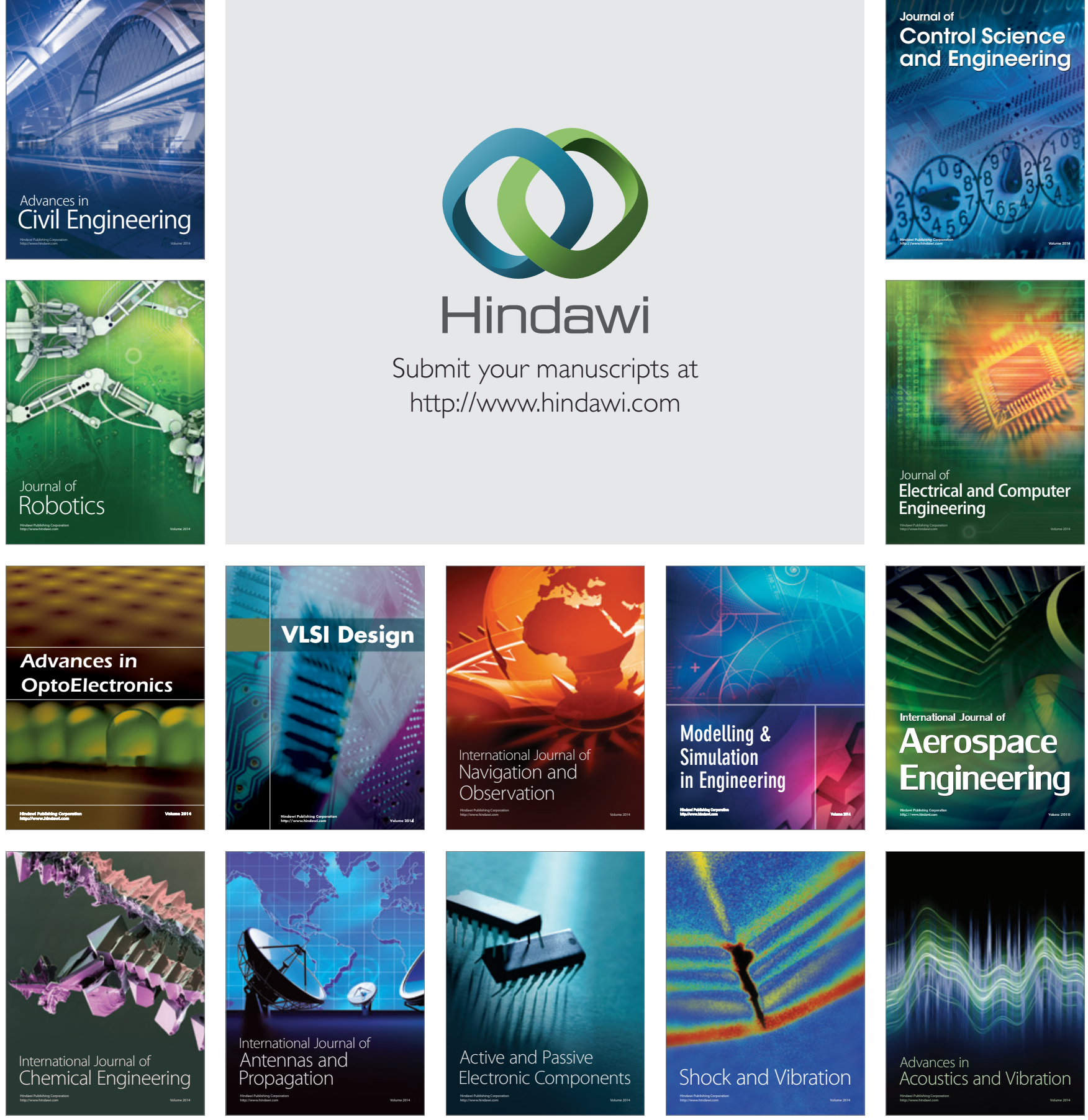